\title{
Review
}

\section{City Noise-Air: An environmental quality index for cities}

\author{
Lígia T. Silva*, José F.G. Mendes \\ Department of Civil Engineering, University of Minho, Braga, Portugal
}

\section{A R T I C L E I N F O}

\section{Keywords:}

Urban air pollution

Urban noise

Air pollution modelling

Urban noise modelling

\begin{abstract}
A B S T R A C T
Global population growth has led to an increase of the number of people living in urban areas. As a consequence, stresses on space, ecosystems, infrastructures, facilities and personal lifestyles have been enhanced. Problems related to the quality of life in cities are increasingly relevant, especially with regard to environmental issues. Domestic and industrial sources and, primarily, motorised traffic are responsible for pollutant emissions and noise that decisively affect life in modern cities. In this context, evaluating and monitoring urban environmental quality has become an important issue for decision making and planning of more liveable and sustainable cities. Computational simulation models for the phenomena associated with emission and propagation of noise and dispersion of air pollutants were applied within a GIS platform to generate maps of noise and pollutant concentrations. This paper presents an urban environmental quality index: City Noise-Air. In case either one of the environmental conditions (pollutants or noise level) exceeds the accepted limit, the City Noise-Air index will reflect that exceedance and thus equals zero (red). If there is no limit violation, then City Noise-Air incorporates all of the selected conditions into an overall quality index by a multi-criteria combination that allows trade-offs. A case study is presented for Viana do Castelo, a mid-sized Portuguese city, in which City NoiseAir values were calculated taking in consideration the noise level $\left(L_{\mathrm{den}}\right)$ and the concentrations of CO, $\mathrm{NO}_{2}, \mathrm{O}_{3}, \mathrm{C}_{6} \mathrm{H}_{6}$ and PM10.
\end{abstract}

\section{Contents}

1. Introduction

1.1. Urban air pollution.

1.2. Urban noise pollution

2. The City Noise-Air index....

2.1. CityAir formulation.............

$3_{3}$

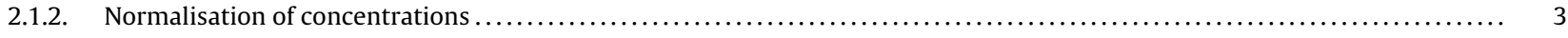

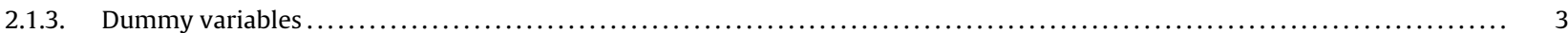

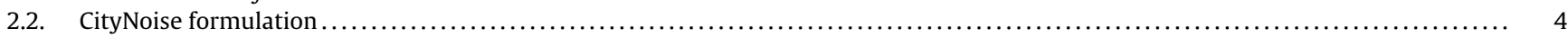

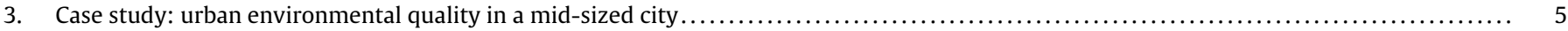

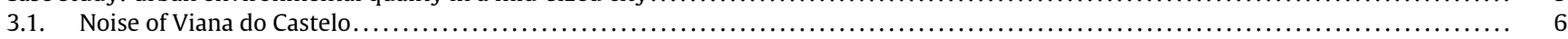

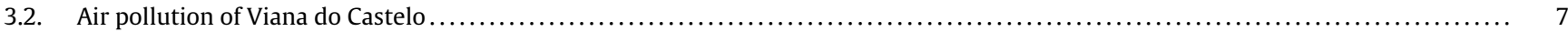

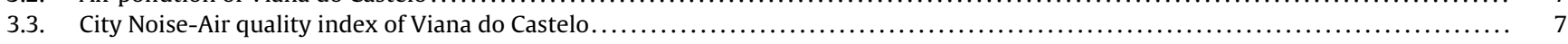

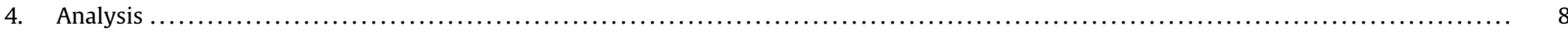

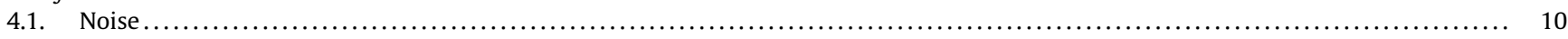

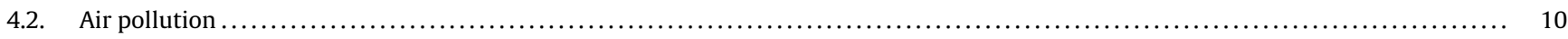

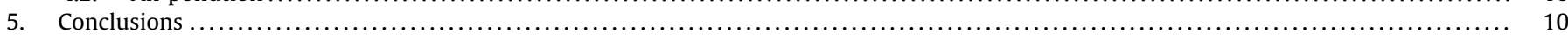

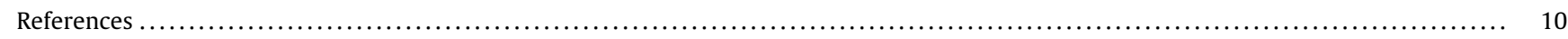

\footnotetext{
* Corresponding author at: Department of Civil Engineering, University of Minho, Campus Gualtar, 4710 - Braga, Portugal. Tel.: +351 253 604726; fax: +351 253604721.

E-mail address: Isilva@civil.uminho.pt (L.T. Silva).
} 


\section{Introduction}

Urban air pollution and urban noise are major factors that can degrade quality of life in cities. These problems are generally worsening due to the unbalanced urban development and increasing mobility and road traffic. As a consequence, the total emissions and noise from road traffic have risen significantly and have been primarily responsible for violations of air and noise quality standards.

Motorised traffic is nowadays recognised as the major contributor to environmental noise in urban areas, mainly due to engine noise and rolling noise from tyre friction on the road surface (Boschmann \& Kwan, 2008; King, Murphy, \& McNabola, 2009; OECD, 1995). Similarly, automobile traffic is the dominant source of air pollution (O'Mahony, Gill, Broderick, English, \& Ahern, 2006).

Usually air and noise pollution are considered separately. The combination of noise exposure and air quality analysis applied to a specific location along the riverside boardwalk in Dublin, was firstly proposed by King et al. (2009). These authors developed an air-noise pollution reduction index $\left(\mathrm{ANP}_{\mathrm{r}}\right)$ to measure and assess the combined reduction and assessment of air and noise pollution along the boardwalk and footpath areas. The study concludes that this index has considerable potential for use in aiding the decisionmaking process of urban planners and policy makers in a variety of urban contexts.

This paper proposes a long-term model for urban air pollution and noise that allows for the combined assessment of noise and air pollution within an urban context, and presents an application study to a mid-sized Portuguese city.

\subsection{Urban air pollution}

After emission from a variety of extant sources, atmospheric pollutants are transported and dispersed several times in the atmosphere before reaching receptors through wet deposition (rainout and washout by rain and snow) or dry deposition (particle adsorption). In an urban environment, typical anthropogenic sources are road traffic and industrial activities. Emissions from mobile sources contribute to primary and secondary air pollution that can threaten human health, damage ecosystems and influence climate (Nagurney, Qiang, \& Nagurney, 2010; Sharma, Kharol, \& Badarinath, 2010). Traffic patterns, vehicle characteristics and street configurations have a cumulative effect on exhaust emissions (Pandian, Gokhale, \& Ghoshal, 2009).

Compounds released into the atmosphere from motor vehicle exhaust have an impact on the environment at various geographical and time scales (Highways Agency, 2007). Certain compounds possess an immediate and local effect. For instance, a plume of black smoke is instantly unpleasant for observers, and chronic releases of black smoke can darken the facades of buildings through particle deposition.

Combustion of hydrocarbon fuel in air generates mainly carbon dioxide $\left(\mathrm{CO}_{2}\right)$ and water $\left(\mathrm{H}_{2} \mathrm{O}\right)$. However, combustion engines are not totally efficient, and not all of the fuel is oxidised. The products of incomplete combustion are more complex and may include hydrocarbons and other organic compounds as well as benzene $\left(\mathrm{C}_{6} \mathrm{H}_{6}\right)$, carbon monoxide $(\mathrm{CO})$ and particulate matter (PM) containing carbon and other pollutants. Additionally, combustion under high pressure and temperature conditions causes partial oxidation of nitrogen in air and fuel, which forms nitrogen oxides, such as nitric oxide and some nitrogen dioxides (conventionally designated as $\mathrm{NO}_{x}$ ). Amongst the hydrocarbons, benzene is the compound with the greatest environmental impact due to its toxicity and its carcinogenicity (ATSDR, 1997). Many of the atmospheric pollutants derived from motor vehicles react with air components or with each other to form compounds called secondary pollutants. Due to dispersion effects, the concentrations of secondary pollutants typically do not reach maximum values near the emission sources; its impact can extend over large areas beyond the immediate vicinity of road traffic.

Traffic-related air pollution levels can be evaluated by either direct measurements or predictive models. The direct measurement method is only feasible for evaluating actual situations; predictive methods can be applied throughout the planning process from the initial concept to the final detailed design of air pollution abatement measures. However, measurements provide essential information to validate the predictive methods.

There are numerous dispersion models available, which represent an important set of tools for simulating air pollution scenarios. The model adopted for this research was developed by Cambridge Environmental Research Consultants (CERC) in the United Kingdom. This model has been used by local authorities all over Europe for urban air quality forecasting (Carruthers, Blair, \& Johnson, 2003; Carruthers et al., 1997; Carruthers, Edmunds, Lester, McHugh, \& Singles, 1998; McHugh, Carruthers, \& Edmunds, 1997; Sabatino, Buccolieri, and Bitter, 2005; Timmis, Wilkinson, Carruthers, \& McHugh, 2000). The model uses a parameterisation of boundary layer physics in terms of boundary layer depth and Monin-Obukhov length, and then applies a skewed-Gaussian concentration profile for convective meteorological conditions. For stable and neutral meteorological conditions, the model assumes a Gaussian plume for the concentration profile distribution with reflection at the ground and in the inversion layer.

The dispersion model has a methodological processor for input variables, which typically include day of the year, time of day, cloud cover, wind speed and temperature. These variables are used to calculate model parameters such as boundary layer depth and Monin-Obukhov length. The model does not account for anthropogenic heat sources.

An additional and important feature that makes this dispersion model suitable for modelling the urban environment is a chemistry scheme that facilitates the calculation of chemical reactions between nitric oxide, nitrogen dioxide, ozone and volatile organic compounds in the atmosphere.

\subsection{Urban noise pollution}

Although the exposure of communities to environmental noise is a worldwide concern, most cities are still subjected to noise levels that are a disturbance to human activities. The health effects of environmental noise are well-documented. Traffic noise can cause numerous health problems such as sleep disturbance, high blood pressure and psycho-physiological symptoms (King \& Davis, 2003; Ko, Chang, Kim, Holt, \& Seong, 2011; King et al., 2009; WHO, 2011).

According to WHO (2011), 33\% of the individuals are annoyed during the daytime and $20 \%$ have disturbed sleep at night because of traffic noise. Traffic-related noise is becoming the most healththreatening environmental stressors in Europe, and more people are exposed to traffic-related noise than to any other environmental stressors (WHO, 2011).

Traffic-related noise levels can be evaluated by predictive models complemented with direct measurements. The measurements provide essential information to validate the predictive methods (Murphy \& King, 2010a,b).

Numerous noise prediction models are available and thus constitute an important toolbox for simulating the acoustic situation, as discussed by Bertellino and Licitra (2000).

The model adopted for this research is the New Method of Forecast of the Traffic Noise (NMPB 96), which was developed in France in 1996. This method is the recommended interim computation method for road traffic noise calculation by European Parliament Directive 2002/49/EC and the Council of June 25, 2002 (Directive 2002/49/EC, 2002), which addressed the assessment 
and management of environmental noise. The NMPB 96 calculates the acoustics for each ray issued from a receptor that cuts a source line. If the angular step is sufficiently small (several degrees), the topography represented by the segments intersected by the ray is assumed not to vary in the angular cone; in other words, it is assumed that the propagation medium does not vary in the cone. Under these conditions, the problem is simplified to the calculation of a cross sectional cut between a point source and a receptor. This calculation requires definitions for acoustic power associated with the cross section, attenuation by the geometric divergence $\left(A_{\text {div }}\right)$, absorption by the air $\left(A_{\mathrm{atm}}\right)$, diffraction $\left(A_{\mathrm{dif}}\right)$, ground effects ( $\left.A_{\text {ground }}\right)$, and absorption by the vertical surfaces $\left(A_{\text {ref }}\right)$ on which the ray has been reflected in the horizontal plane.

The calculations are performed for the three long-term sound level indicators: $L_{\text {day }}$ (represents the A-weighted equivalent sound level of all the day periods of a year $\left(p_{\text {day }}\right)$ ), $L_{\text {evening }}$ (represents the A-weighted equivalent sound level of all the evening periods of a year $\left(p_{\text {evening }}\right)$ ) and $L_{\text {night }}$ (represents the A-weighted equivalent sound level of all the night periods of a year $\left(p_{\text {night }}\right)$ ). The $L_{\text {den }}$ indicator is calculated from $L_{\text {day }}, L_{\text {evening }}$ and $L_{\text {night }}$ values according to Eq. (1).

$$
\begin{aligned}
& L_{\text {den }}=10 \log \left(\frac{1}{24}\right) \cdot\left(p_{\text {day }} 10^{\left(L_{\text {day }} / 10\right)}+p_{\text {ev. }} \cdot 10^{\left(\left(L_{\text {evening }}+5\right) / 10\right)}\right. \\
& \left.+p_{\text {night }} \cdot 10^{\left(\left(L_{\text {night }}+10\right) / 10\right)}\right)
\end{aligned}
$$

where in compliance to Portuguese legislation (DR, 2007), $p_{\text {day }}=13 \mathrm{~h}$ (day period between the hours of 07:00 and 20:00); $p_{\text {ev. }}=3 \mathrm{~h}$ (evening period between 20:00 and 23:00); and $p_{\text {night }}=8 \mathrm{~h}$ (night period between 23:00 and 7:00).

Although the method has been simplified, the City Noise-Air index could be applied to any noise calculation method, namely in the recently released version of NMPB-Routes-2008.

\section{The City Noise-Air index}

The proposed City Noise-Air model is based on both long-term noise levels and long-term air pollutant concentrations that were either historically measured or derived from mathematical simulation models. Modelled data can provide a predictive view of urban environmental quality.

The City Noise-Air index results from the weighted linear combination (WLC) of two normalised indexes: cityNoise and cityAir (Eq. (2)):

City Noise-Air $=(0.5 \times$ cityNoise $+0.5 \times$ cityAir $)$

where cityNoise is the normalised index of urban noise quality, and cityAir is the normalised index of urban air quality.

The numerical value of the City Noise-Air index varies between 0 and 1. City Noise-Air is equal to zero when the noise level is above the legal limit and at least one air pollutant concentration is above the limit value. On the other hand, City Noise-Air is equal to one when the noise level is below the limit value and all of the air pollutant concentrations are at or below the values recommended by WHO $(2005,2009)$.

\subsection{CityAir formulation}

The proposed CityAir model compiles long-term concentration data from historical measurements or, alternatively, from mathematical simulation models to predict air quality.

Air pollution concentrations in a city are simulated and the values for each point or area are compared with a standard limit (in this paper, the legal limit). This comparison generates a dummy variable: zero if the standard is exceeded and unity if it is not.
The cityAir index results from the weighted linear combination of normalised concentration values, which are subjected to the product of the dummy variables (Eq. (3)):

cityAir $=\sum_{i} w_{i} c_{i} \times \prod_{i} v_{i}$

where $w_{i}$ is the relative weight of the pollutant $i ; c_{i}$ is the normalised concentration of the pollutant $i$; and $v_{i}$ is the dummy variable of the legal limit violation $L_{i}$ of pollutant $i$, defined as follows:

$v_{i}=1$ when $c_{i} \leq L_{i}$

$v_{i}=0$ when $c_{i}>L_{i}$

The proposed model makes use of multi-criteria techniques for combining, aggregating and standardising pollutant concentration data.

\subsubsection{Pollutant weights}

The pollutants selected for inclusion in the cityAir index may vary according to source type or data availability. The current paper presents the pollutants considered in the case study, all of which typically result from road traffic:

- CO: carbon monoxide

- $\mathrm{NO}_{2}$ : nitrogen dioxide

- PM10: particulate matter $<10 \mu \mathrm{m}$

- $\mathrm{C}_{6} \mathrm{H}_{6}$ : benzene

- $\mathrm{O}_{3}$ : ozone

Equal weights were considered, which means that the value of 0.2 was adopted for each of the five pollutants.

\subsubsection{Normalisation of concentrations}

Because concentration data were measured in different scales, they must be standardised prior to aggregation. The process of standardisation is essentially identical to that of fuzzification in fuzzy sets. Standardisation is intended to transform any scale into a normalised range (i.e., zero to one). In the present case, the results express a membership grade that ranges from 0.0 to 1.0 , representing a continuous spectrum from non-membership (bad air quality) to complete membership (very good air quality) on the basis of the criterion (pollutant concentration) being fuzzified. (4)):

A sigmoidal function has been adopted for standardisation (Eq.

score $=\frac{1}{\sin ^{2} \alpha}=\cos ^{2} \alpha$

where

$\alpha=\left[\frac{\left(x-x_{a}\right)}{\left(x_{b}-x_{a}\right)}\right] \times \frac{\pi}{2}$

where $x$ is the concentration value being normalised, and $x_{a}$ and $x_{b}$ are control points in the function. Fig. 1 presents this function graphically for each of the five pollutants. The control points adopted $(a$ and $b$ ) are listed in Table 2 .

The control points of the sigmoidal functions were selected according to the following criteria: score $=0$ for the concentration limit values considered in the Portuguese legislation for human health protection and score $=1$ for the concentration guidance values recommended by the World Health Organisation (WHO, 2005), $\mathrm{NO}_{2}$ and $\mathrm{CO}$ values represented a non-polluted atmosphere (Seinfeld \& Padis, 1997). Table 1 presents the adopted values.

\subsubsection{Dummy variables}

Dummy variables switch from zero to one at the concentration limits mentioned above (third column of Table 1 ). Fig. 2 shows a graphical view of the dummy variable functions. 

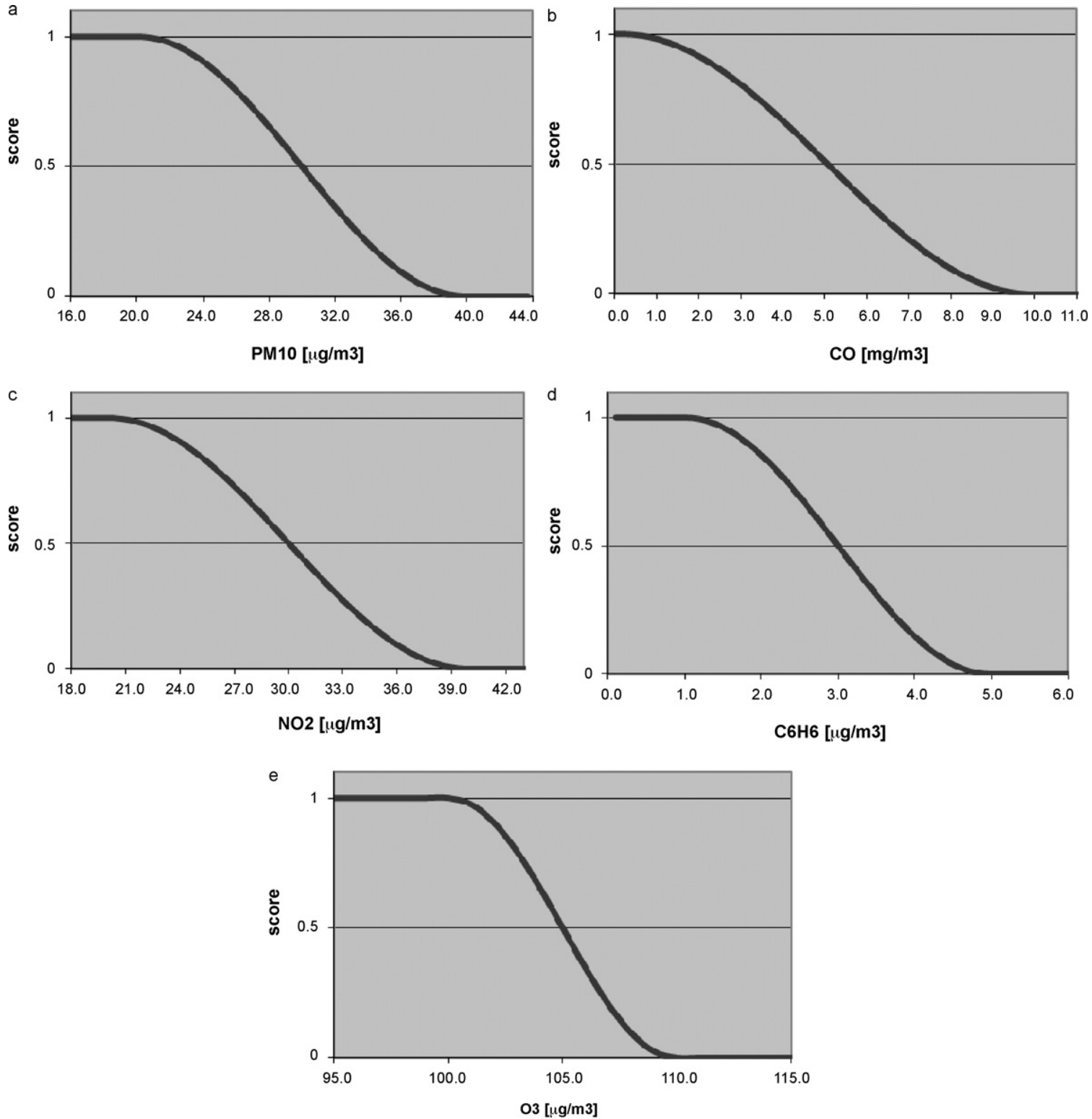

Fig. 1. Normalisation functions. Fuzzy function of (a) $\mathrm{PM} 10$, (b) $\mathrm{CO}$, (c) $\mathrm{NO}_{2}$, (d) $\mathrm{C}_{6} \mathrm{H}_{6}$, and (e) $\mathrm{O}_{3}$.

\subsection{CityNoise formulation}

The proposed cityNoise model utilises the long-term noise indicator $L_{\text {den }}$ (day-evening-night noise indicator), as defined by EU Directive 2002/49/EC. Data may include historical measurements or mathematically simulated results. Noise levels in a city are simulated, the values for each point or area are compared with a standard (in this paper, selected limits reflect the acoustical classification). The value is zero when the limit is exceeded and equals one if it is not.
Based on the land-uses established by the Master Plan and Portuguese Legislation (DR, 2007), the acoustic zoning map classifies land into two classes: "sensitive areas," which currently are (or likely will be) used for residences, schools, hospitals, recreation and leisure; and "mixed areas," which include sensitive uses as well as retail shops and services, parking, etc. This legislation forces the consideration of outdoor noise levels in the planning process and specifically in the elaboration of zoning plans. The law prescribes weighted average sound level standards for the entire day $\left(L_{\mathrm{den}}(\mathrm{A})\right)$ and for the night $\left(L_{\mathrm{n}}(\mathrm{A})\right)$. Sensitive areas may not be exposed to an

Table 1

Control points of the fuzzy functions.

\begin{tabular}{|c|c|c|c|}
\hline & Score $=0$ & Score $=1$ & Averaging period \\
\hline $\mathrm{CO}$ & {$[\mathrm{CO}]>10.0 \mathrm{mg} / \mathrm{m}^{3}$} & {$[\mathrm{CO}] \leq 0.140 \mathrm{mg} / \mathrm{m}^{3}$} & $8 \mathrm{~h}$ (rolling average) for calendar year \\
\hline PM & {$[\mathrm{PM} 10]>40.0 \mu \mathrm{g} / \mathrm{m}^{3}$} & {$[\mathrm{PM} 10] \leq 20.0 \mu \mathrm{g} / \mathrm{m}^{3}$} & Calendar year \\
\hline $\mathrm{NO}_{2}$ & {$\left[\mathrm{NO}_{2}\right]>40.0 \mu \mathrm{g} / \mathrm{m}^{3}$} & {$\left[\mathrm{NO}_{2}\right] \leq 20.0 \mu \mathrm{g} / \mathrm{m}^{3}$} & Calendar year \\
\hline $\mathrm{O}_{3}$ & {$\left[\mathrm{O}_{3}\right]>110.0 \mu \mathrm{g} / \mathrm{m}^{3}$} & {$[03] \leq 100.0 \mu \mathrm{g} / \mathrm{m}^{3}$} & 8-h average for calendar year \\
\hline $\mathrm{C}_{6} \mathrm{H}_{6}$ & {$\left[\mathrm{C}_{6} \mathrm{H}_{6}\right]>5.0 \mu \mathrm{g} / \mathrm{m}^{3}$} & {$[\mathrm{C} 6 \mathrm{H} 6] \leq 1.0 \mu \mathrm{g} / \mathrm{m}^{3}$} & Calendar year \\
\hline
\end{tabular}



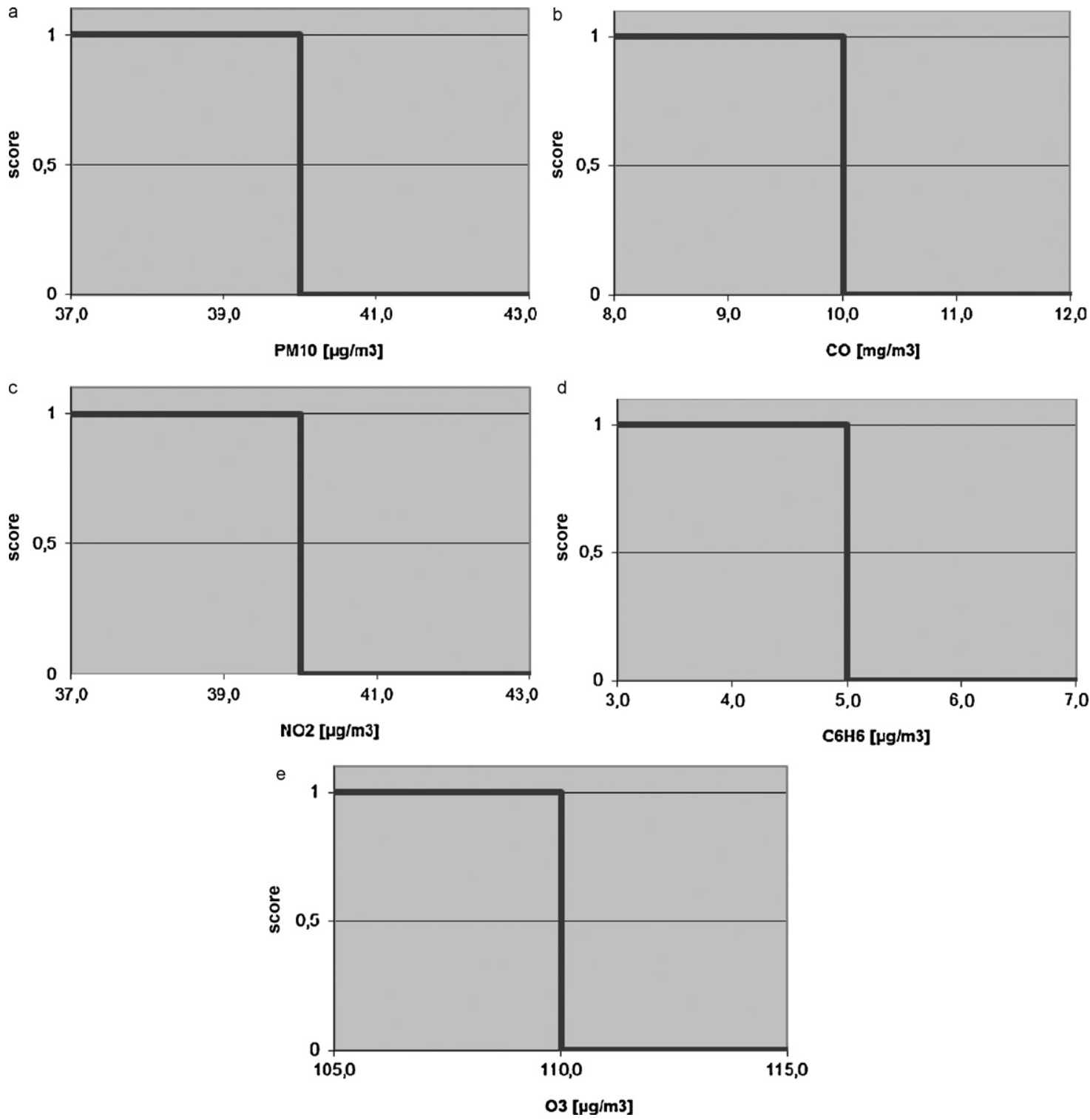

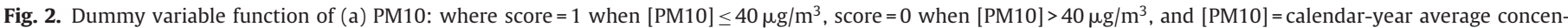

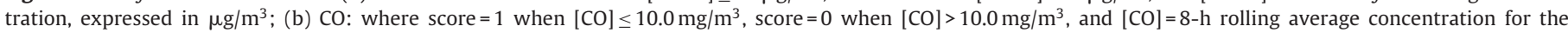

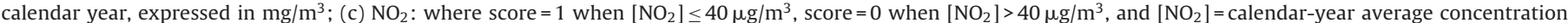

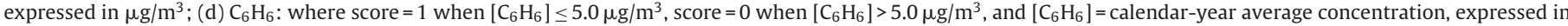

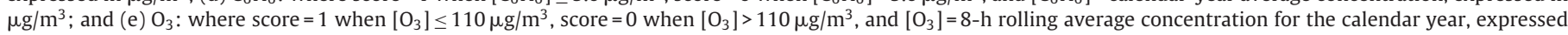
in $\mathrm{mg} / \mathrm{m}^{3}$.

equivalent continuous sound level higher than $55 \mathrm{~dB}(\mathrm{~A})$ during the entire day (average value over the day, evening and night periods), and $45 \mathrm{~dB}(\mathrm{~A})$ during the night; mixed areas may not be exposed to more than $65 \mathrm{~dB}(\mathrm{~A})$ during the entire day and $55 \mathrm{~dB}(\mathrm{~A})$ during the night.

The cityNoise index results from the normalisation of the $L_{\mathrm{den}}$ values. A sigmoidal function has been adopted for this process (Eq. (4)), where $x$ is the $L_{\mathrm{den}}$ value being normalised, and $x_{a}$ and $x_{b}$ are control points in the function. Fig. 3 shows a graphical view of this function for sensitive areas.
The control points of the sigmoidal function were selected according to the following criteria: score $=0$ for the limit value of the annoyance indicator $L_{\mathrm{den}}$; and score $=1$ for the limit value of the sleep indicator $L_{\mathrm{n}}$. Table 2 presents the adopted values.

\section{Case study: urban environmental quality in a mid-sized city}

A case study was undertaken to evaluate the urban environmental quality in the Portuguese city of Viana do Castelo, which

Table 2

Control points of the fuzzy function for noise.

\begin{tabular}{|c|c|c|c|}
\hline & Score $=0$ & Score $=1$ & Averaging period \\
\hline$L_{\mathrm{den}}($ sensitive areas) & $L_{\mathrm{den}}>55 \mathrm{~dB}(\mathrm{~A})$ & $L_{\mathrm{den}}<45 \mathrm{~dB}(\mathrm{~A})$ & Calendar year (long-term average) \\
\hline$L_{\text {den }}$ (mixed areas) & $L_{\mathrm{den}}>65 \mathrm{~dB}(\mathrm{~A})$ & $L_{\mathrm{den}}<55 \mathrm{~dB}(\mathrm{~A})$ & Calendar year (long-term average) \\
\hline
\end{tabular}




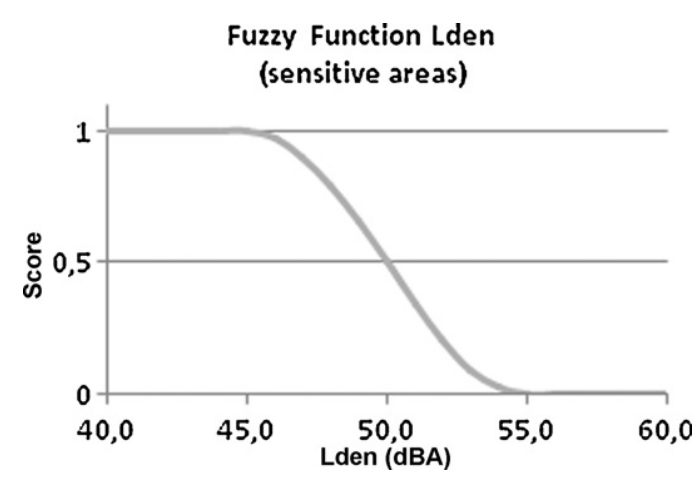

Fig. 3. Normalisation function for $L_{\mathrm{den}}$ for sensitive areas.

is located in the north-western seaside. This mid-sized city has a population of around 36,000 in an overall area of $37 \mathrm{~km}^{2}$. The most notable source of noise and air pollution is a main road (Avenida 25 de Abril) that crosses the city, dividing it into two parts.

Based on traffic data and the physical characteristics of the area, horizontal noise maps and horizontal concentration maps were created for five main pollutants: $\mathrm{CO}, \mathrm{NO}_{2}, \mathrm{C}_{6} \mathrm{H}_{6}, \mathrm{PM} 10$ and $\mathrm{O}_{3}$. A range of numerical models were used to produce results. The New Method of Forecast of the Traffic Noise (NMPB 96) was used to develop noise maps. The ADMS-Urban model was used for pollutant dispersion. The hills model was used to calculate air flow and turbulence over complex terrain and to account for the effects of variable surface roughness (CERC, 2001). The COPERT4 model (COPERT4), which is based on CORINAIR v.5 (CORINAIR, 2006), was used to estimate traffic emissions.

\subsection{Noise of Viana do Castelo}

The modelling of outdoor acoustic propagation in built up urban areas must integrate all the parameters that influence its propagation, such as the topography, the location, the screens, the nature of the ground and the meteorological conditions, amongst others.

For the acoustic characterization of the sources, and considering that Viana do Castelo is a tourist seaside city, two traffic counting campaigns were carried out, one in winter time and another one in summer time, of which resulted the data for two scenarios. Each campaign included most of the city streets and traffic was counted round-the-clock in a typical week day.

A full survey, including topographic characteristics, sound absorption characteristics of the ground, presence of natural and artificial barriers, and the specification of the emission sources (profile, cross section and pavements of streets) was carried out for the whole city. The noise maps have been made for a height of $1.2 \mathrm{~m}$, as this height was the recommendation of NP 1730 (1996) and corresponds approximately to the height of the ears of a person. The same height was adopted to the air pollution maps in the following section. In order to validate the noise map produced for the city of Viana do Castelo a measurement campaign was undertaken to establish environmental noise levels in the city. In accordance with APA (2008) and with NP 1730 methodology, three long-term measurements were carried out. The site selection was undertaken according to the following criteria: predominant influence of one type of source, predicted values exceeding the regulatory requirements (hot spots) within the perimeter of the urbanised area closest to the source, and doubtful results. The measurements were made over two typical days. In each case the measurement height was $1.2 \mathrm{~m}$, carried out away from the façade of buildings ( $\geq 4 \mathrm{~m}$ ). The comparison between measurements taken on-site and the noise map has confirmed the generally good performance of the model. It was found that $L_{\mathrm{den}}$ measured levels were generally within $3 \mathrm{~dB}(\mathrm{~A})$ of the $L_{\mathrm{den}}$ predicted levels (Silva, 2008).

The model utilised the accumulated data to produce horizontal noise maps for winter and summer traffic scenarios. These maps should be interpreted as long-term maps. The following calculation parameters were adopted:

Grid spacing: software-generated variable grid spacing (less than $10 \mathrm{~m})$;

Height of the map: $1.20 \mathrm{~m}$;

Occurrence of favourable meteorological conditions: in compliance to WG-AEN (2006), day period 50\% $(p=0.5)$; evening period $75 \%(p=0.75)$; night period $100 \%(p=1)$;

Number of rays: 50; distance propagation: $250 \mathrm{~m}$;

Reflection order: 2nd;

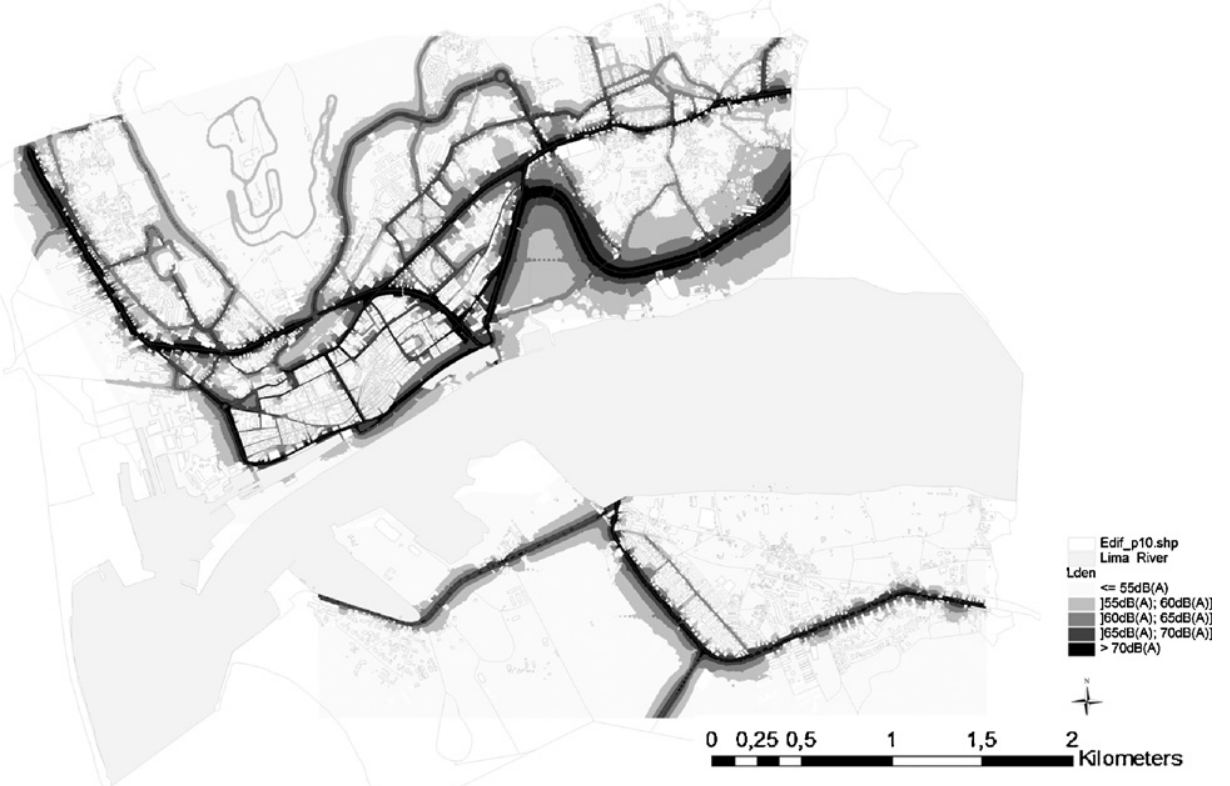

Fig. 4. Noise map, summer scenario, $L_{\mathrm{den}}$ (Silva, 2008). 
Table 3

Population and area exposed to noise.

\begin{tabular}{lcr}
\hline Noise level $L_{\mathrm{den}}[\mathrm{dB}(\mathrm{A})]$ & \multicolumn{2}{c}{ Summer scenario } \\
\cline { 2 - 3 } & Population (\%) & Area (\%) \\
\hline$\leq 35$ & 4.98 & 13.02 \\
$\leq 40$ & 4.12 & 6.62 \\
$\leq 45$ & 10.84 & 10.11 \\
$\leq 50$ & 14.19 & 13.59 \\
$\leq 55$ & 18.53 & 16.21 \\
$\leq 60$ & 16.31 & 15.35 \\
$\leq 65$ & 14.00 & 11.30 \\
$>65$ & 17.03 & 13.80 \\
Total & 100.00 & 100.00 \\
\hline
\end{tabular}

Output: $L_{\mathrm{den}}(\mathrm{A})$ day-evening-night period, long-term average $[\mathrm{dB}(\mathrm{A})]$;

Road surface: variable; average speed: variable.

In this article, the results are presented for the most critical scenario: the summer scenario (Fig. 4).

The 2001 population data, obtained from the Census Bureau CENSO2001 and georeferenced to the smallest geographical spatial unit available - the census block, was stored in a topological GIS coverage and overlaid together with the $L_{\text {den }}$ map in order to find out the percentage of people and territory exposed to noise above the legal limits. For this purpose, a uniform distribution of the population within the blocks was assumed. The results can be observed in Tables 3 and 4.

\subsection{Air pollution of Viana do Castelo}

The characterization data of the sources was originated from the two traffic counting campaigns as described in the previous section. Main and secondary roads were modelled explicitly, as was one pulp and paper mill located in the vicinity of the city. This factory was modelled as one point source that represents the stack. One single profile was developed to represent the hourly variation of traffic flows on all the roads. A full survey, including topographic characteristics, surface roughness and the specification of the emission sources, and cross and longitudinal profiles (for canyon roads) was carried out for the whole city.

The methodology adopted for the validation of urban air dispersion model was based in BOOT statistical approach, deriving from that of Hanna and Paine (1989). The calculated statistics include mean, standard deviation, normalised mean square error, normalised bias and the FAC2. The pollutant used in the validating process was $\mathrm{CO}$, a primary and typical road pollutant. The pollutants were measured at three monitoring sites in the city over three typical days. The validation process was developed at two levels: (a) averaging the data in order to obtain daily concentration profiles, both for monitored and predicted data; (b) for each monitoring site, comparison of the averaged daily concentration profiles by the BOOT statistical methodology. The comparison of the modelled values with pollutant concentrations measured in the control points

Table 4

Population and territory exposed to noise level above the legal limits.

\begin{tabular}{llc}
\hline \multirow{2}{*}{ Census blocks } & \multicolumn{2}{l}{ Summer scenario } \\
\cline { 2 - 3 } & Population (\%) & Area (\%) \\
\hline Areosa & 12.6 & 12.4 \\
Darque & 11.7 & 5.8 \\
Meadela & 11.8 & 24.7 \\
Monserrate & 20.1 & 19.1 \\
Santa Maria Maior & 25.5 & 34.1 \\
\hline
\end{tabular}

Table 5

Areas and populations affected by air pollution.

\begin{tabular}{lcc}
\hline \multirow{2}{*}{ cityAir } & \multicolumn{2}{c}{ Summer scenario } \\
\cline { 2 - 3 } & Population (\%) & Area (\%) \\
\hline$=0$ & 0.2 & 0.2 \\
$<0.35$ & 0.0 & 0.0 \\
$<0.65$ & 0.0 & 0.0 \\
$<0.85$ & 71.7 & 47.3 \\
$\leq 1.0$ & 28.0 & 52.4 \\
Total & 100 & 100 \\
(Silva, 2008) & & \\
\hline
\end{tabular}

has confirmed the generally good performance of the model (see Silva, 2008; Silva, Mendes, \& Ramos, 2010).

Horizontal concentration maps were created using ADMSUrban model. These maps represent the average atmospheric pollution situation in one year. The following calculation parameters were adopted:

Grid spacing: variable grid spacing (less than $10 \mathrm{~m}$ );

Height of the map: $1.20 \mathrm{~m}$;

Meteorological conditions: data gathered at the automatic monitoring sites for one year (hourly);

Monin-Obukhov length: $30 \mathrm{~m}$;

Surface roughness: $0.5 \mathrm{~m}$;

Emissions inventory: database prepared for Viana do Castelo including road sources and industrial sources;

Background file: annual average background concentration of $\mathrm{NO}_{2}, \mathrm{CO}, \mathrm{PM} 10$ and $\mathrm{O}_{3}$ at background monitoring sites (Silva, 2008);

Output: hourly average $\mathrm{CO}\left[\mathrm{mg} / \mathrm{m}^{3}\right], \mathrm{NO}_{2}\left[\mu \mathrm{g} / \mathrm{m}^{3}\right], \mathrm{PM} 10\left[\mu \mathrm{g} / \mathrm{m}^{3}\right]$, $\mathrm{C}_{6} \mathrm{H}_{6}\left[\mu \mathrm{g} / \mathrm{m}^{3}\right], \mathrm{O}_{3}\left[\mu \mathrm{g} / \mathrm{m}^{3}\right]$;

Average speed: variable.

This article presents results for the summer scenario, since it is the most critical scenario (Fig. 5a-e).

The combination of the concentration maps, according to Eq. (3), results in an overall air quality map.

Model results were overlain with a population GIS layer to estimate the affected population. Table 5 presents a synthesis of the areas and populations affected by air pollution in the city.

\subsection{City Noise-Air quality index of Viana do Castelo}

According to Eq. (4) and the control points of the fuzzy function for noise (Table 3), noise level values were normalised. CityAir and cityNoise were combined according to Eq. (2), yielding an overall urban environmental quality map. Table 6 presents the classification frame adopted, which considers five categories from Very Poor to Very Good.

The final map of the City Noise-Air quality index across the city for the summer scenario is presented in Fig. 7.

Table 6

City Noise-Air quality classification.

\begin{tabular}{ll}
\hline City Noise-Air & Quality classification \\
\hline$[0 ; 0,2[$ & Very poor \\
{$[0,2 ; 0,4[$} & Poor \\
{$[0,4 ; 0,6[$} & Fair \\
{$[0,6 ; 0,8[$} & Good \\
{$[0,8 ; 1]$} & Very good \\
\hline
\end{tabular}


a
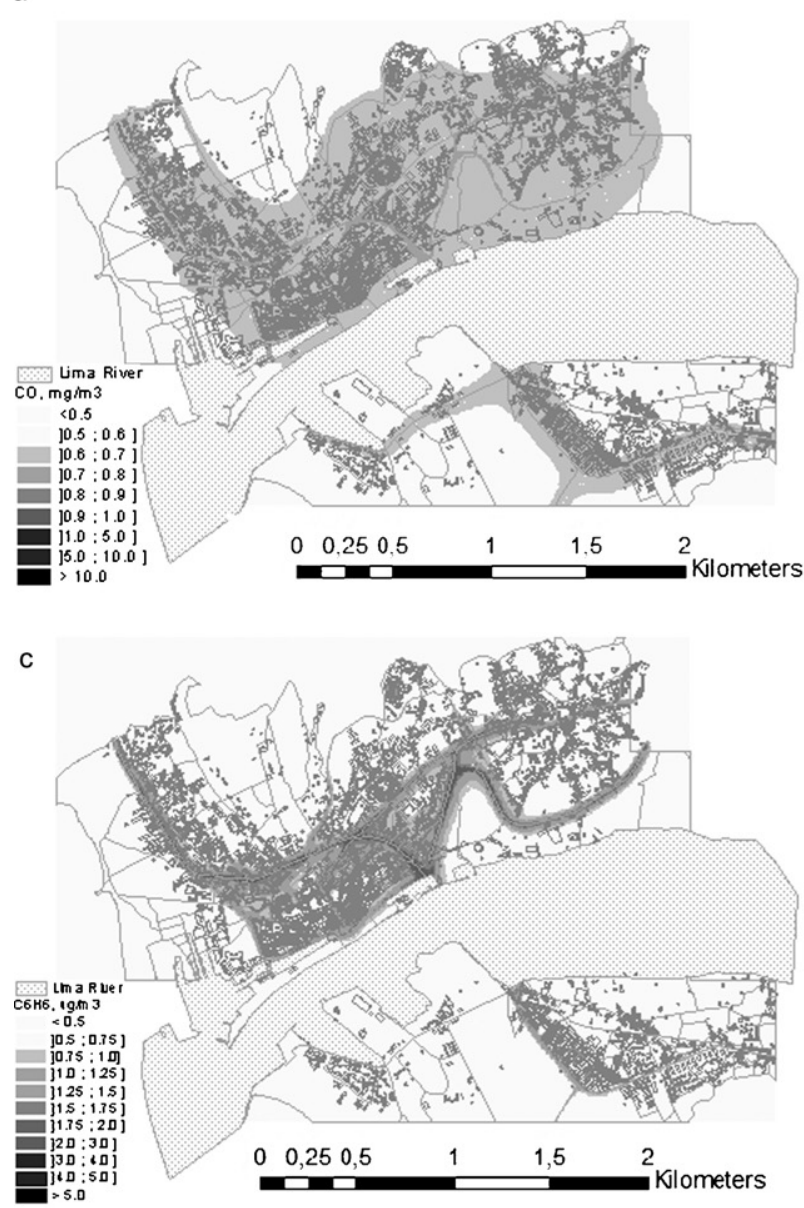
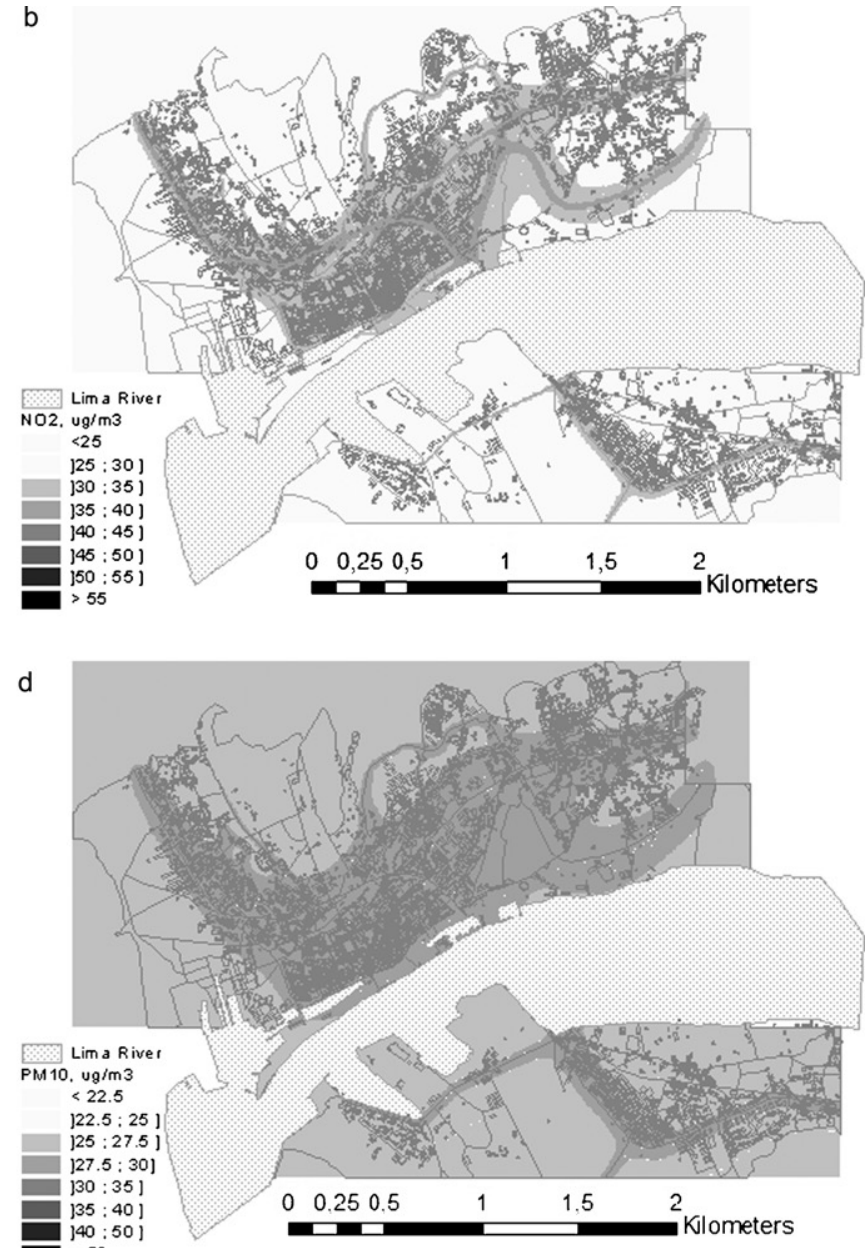

50

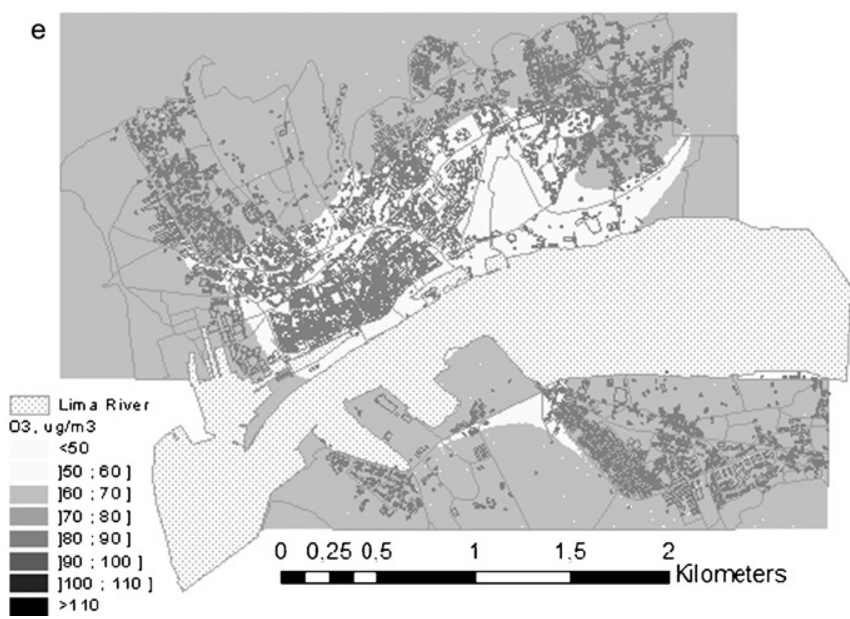

Fig. 5. Air pollution maps, summer scenario: (a) carbon monoxide, $\mathrm{CO}$; (b) nitrogen dioxide, $\mathrm{NO}_{2}$; (c) benzene, $\mathrm{C}_{6} \mathrm{H}_{6}$; (d) particulate matter, PM10; and (e) ozone, $\mathrm{O}_{3}$.

\section{Analysis}

The present work proposes a new urban environmental quality index: City Noise-Air. If at least one of the environmental conditions (pollutants or noise level) exceeds the accepted limit, the City Noise-Air index will reflect that exceedance and return zero (red). If there is no limit violation, then City Noise-Air incorporates all of the selected conditions into an overall quality index by a multi-criteria combination that allows trade-offs.
A case study is presented in which City Noise-Air maps were generated for Viana do Castelo, a mid-sized Portuguese city, based on noise level $\left(L_{\mathrm{den}}\right)$ and concentrations of $\mathrm{CO}, \mathrm{NO}_{2}, \mathrm{O}_{3}, \mathrm{C}_{6} \mathrm{H}_{6}$ and PM10.

Given the seasonal characteristics of the city, two long-term scenarios were developed for summer and winter.

The cityAir index was developed to quantify city air quality. It depends on the concentrations of the five major urban pollutants: $\mathrm{CO}, \mathrm{NO}_{2}, \mathrm{O}_{3}, \mathrm{C}_{6} \mathrm{H}_{6}$ and PM10. 


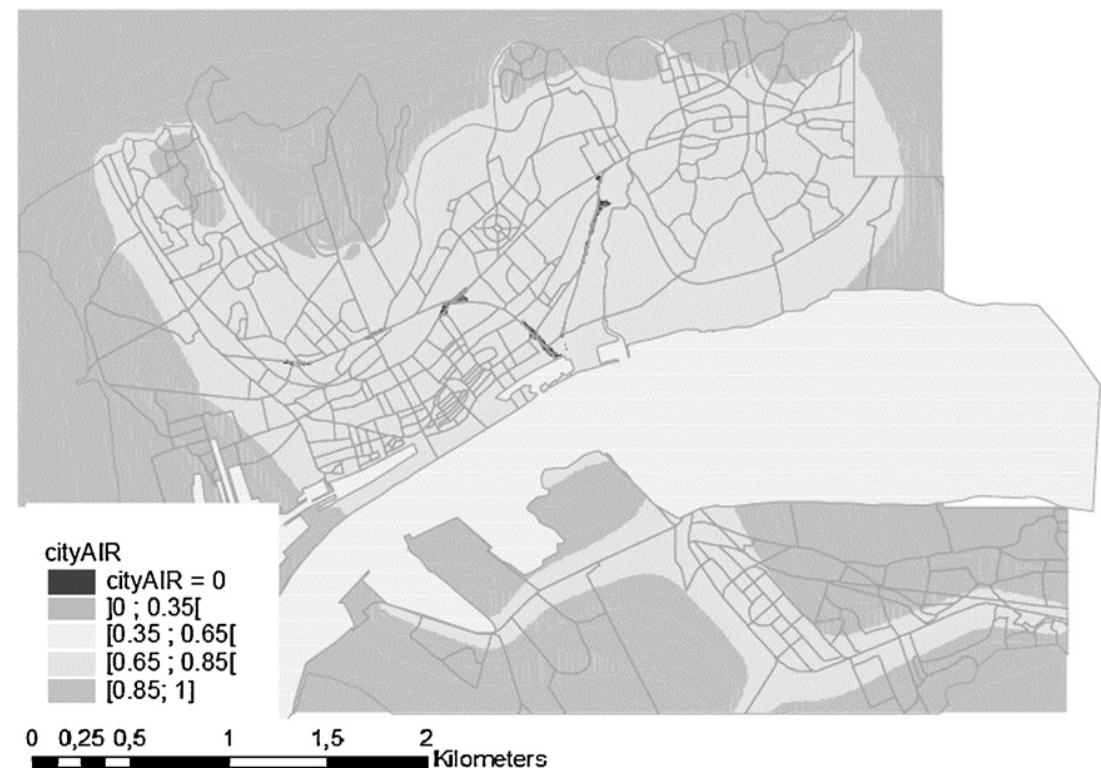

Fig. 6. CityAir, summer scenario.

When none of the concentrations of these pollutants exceeds the legal limit, cityAir is calculated by combining the concentrations of different species. The cityAir index is zero for areas with at least one pollutant concentration above the limit. Each area was also described as a binary data set, whereby a value of one signifies that all concentrations fall below the limit and a value of zero signifies a threshold violation.

In combination with a Geographic Information System platform, the models and technologies used in this study proved to be useful for evaluating urban environmental quality. The predictive noise model is capable of continuously quantifying the city noise levels.
Although the inventory of air pollutant emission sources in the city of Viana do Castelo included one integrated pulp and paper mill, the road traffic sources provide the greatest contribution to air pollution in the city. A dispersion model was used to calculate air pollution in a continuous space of urban pollutant concentrations in the city. Horizontal maps were created for all major air pollutants in urban areas $\left(\mathrm{CO}_{2}, \mathrm{C}_{6} \mathrm{H}_{6}, \mathrm{CO}, \mathrm{NO}_{2}, \mathrm{PM} 10\right.$ and $\left.\mathrm{O}_{3}\right)$. The results demonstrated that the highest concentrations of primary air pollutants occurred in areas adjacent to major roads. The obtained results are in agreement with field measurements and expected values. The highest pollutant concentrations were found in areas with higher

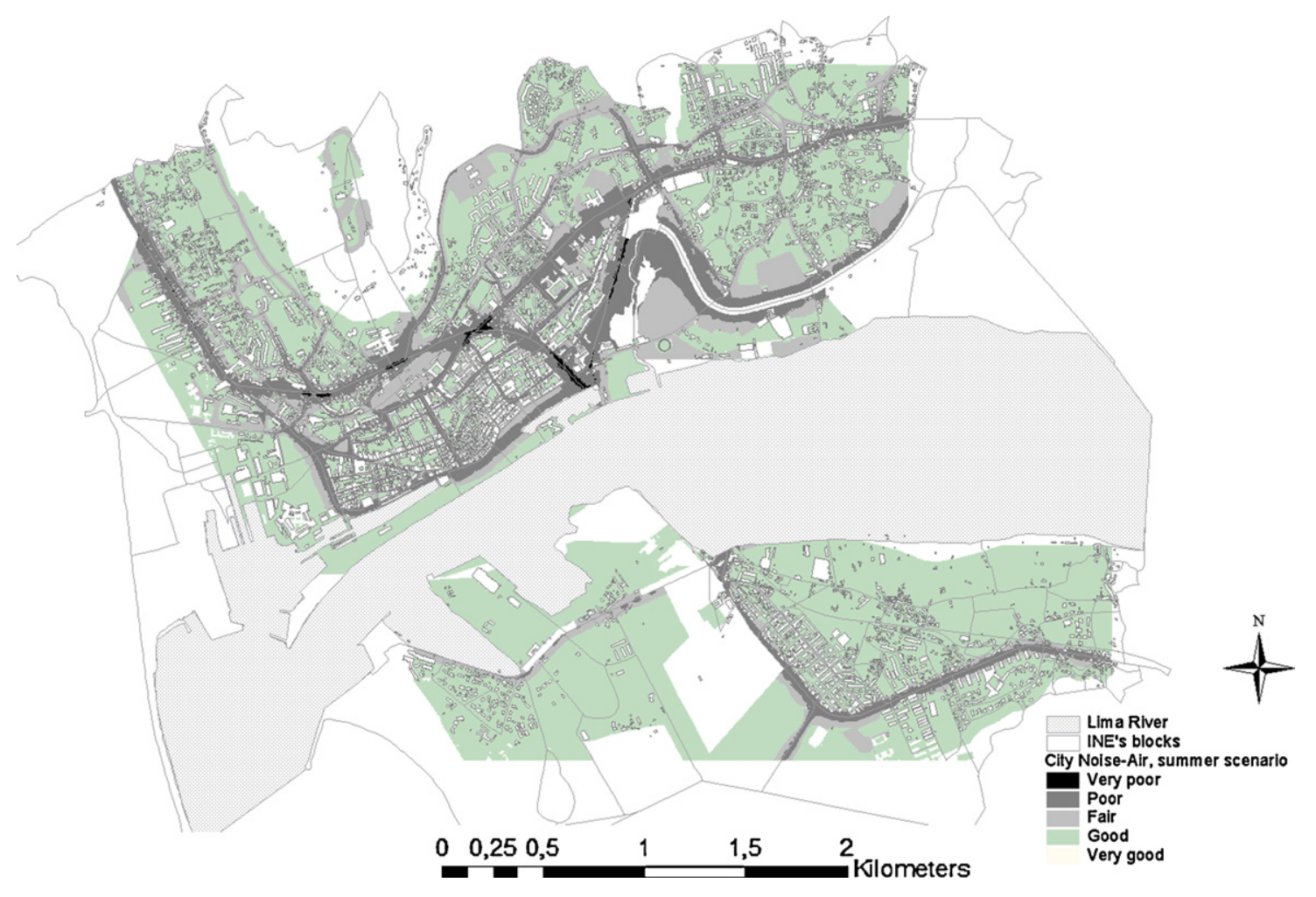

Fig. 7. City Noise-Air, summer scenario. 
traffic flow or on roads with channel characteristics. Additionally, the weather conditions in the summer scenario were relatively unfavourable for dispersion and natural pollutant removal.

The cityAir index defines air quality within a range from zero (poor air quality) to one (good air quality). Applying this model to the city of Viana do Castelo proved very useful for comparing the concentrations of major air pollutant species to their standards. This model generates a summary index of air quality that is easy to understand and intuitive for the general public.

\subsection{Noise}

Based on an analysis of the city noise map (Fig. 4) and of the summary tables, it can be concluded that Monserrate and Santa Maria Maior as the noisiest areas, followed by Meadela, Areosa and finally Darque. About $12 \%$ of the total area of Areosa and about 6\% of Darque were above the legal limits. About $25 \%$ of the total area of Meadela exceeded the limit value. Due to its use, this urban park is classified as acoustically sensitive; observed noise levels indicate that Meadela is a critical area. About 19\% of Monserrate and 34\% of Santa Maria Maior exceeded the legal limits. Due to its high traffic flow, the areas adjacent to Avenida 25 de Abril are identified as acoustically critical areas.

The historic centre (pedestrian zone) appeared to generally comply with the legal limits.

\subsection{Air pollution}

Of all the studied species, only $\mathrm{NO}_{2}$ was found to be above the threshold for human health protection $\left(40 \mu \mathrm{g} / \mathrm{m}^{3}\right)$. Air pollution maps reveal that the concentrations of PM10, $\mathrm{NO}_{2}, \mathrm{CO}, \mathrm{CO}_{2}$ and $\mathrm{C}_{6} \mathrm{H}_{6}$ are higher in areas that are adjacent to high-traffic roads running through and around the city.

Because ozone is a secondary pollutant, its highest concentrations are not found near emission sources. Horizontal maps of $\mathrm{O}_{3}$ show that the maximum ozone concentrations do not exceed the threshold for human health protection $\left(110 \mu \mathrm{g} / \mathrm{m}^{3}\right)$. However, in outlying areas, ozone concentrations reach the threshold for vegetation protection $\left(65 \mu \mathrm{g} / \mathrm{m}^{3}\right)$.

The distribution of the calculated cityAir index across Viana do Castelo revealed that air quality is globally acceptable in this city (Fig. 6). Nonetheless, the dearth of small zones on this map may be problematic. Small zones, including Av. 25 de Abril (the ramp to the bridge), the roundabouts of the hospital and football field and the access to the main road (IC1), have high levels of $\mathrm{NO}_{2}$ above the legal limit.

Based on an analysis of Table 6 , it can be concluded that in the summer only $0.2 \%$ of the population is exposed to a cityAir index of zero.

\section{Conclusions}

The urban environmental quality index used in Viana do Castelo, City Noise-Air, aggregates data for the assessment of air and noise quality of a city and presents results in the context of standardised legal limits for air pollution and noise.

Based on City Noise-Air, several priority areas for future mitigation and monitoring are proposed: Avenida 25 de Abril, Avenida Gaspar de Castro, access to west IC1 and access to north and south EN13.

When the results of this analysis were presented to the Municipality of Viana do Castelo, City Noise-Air index proved to be easily understood and quite intuitive. For the problematic areas, a Monitoring \& Mitigation Plan is being prepared.
In addition to the specific findings for individual areas of the city, it is possible to draw some general conclusions and to appreciate the potential uses of the model herein proposed.

The City Noise-Air index developed here is transparent, simple and easy to understand. Indicator weights and dimensions used in the City Noise-Air calculation depend on the control points defined during the normalisation process. It is also possible to include weighting factors depending on the geographic conditions within particular urban contexts or in situations where it is determined that one pollutant mechanism is more important than others. A variety of options can be used during the City Noise-Air calculation to focus index results on different dimensions and indicators of overall urban environmental quality. Additionally, the dose-effect relationships in relation to the impact of noise and air pollution exposure on human health could be adopted for the standardisation process rather than the sigmoidal functions used here. This would allow the assessment of combined noise and air pollution risk within human health context. However, this is an area where further application and analysis could be considered in the future.

The development of the City Noise-Air index has considerable potential for use in aiding the decision-making process of urban planners and policy makers in a variety of urban contexts. Rather than viewing noise and air pollution impacts separately for planning and environmental sustainability considerations, the possibility of assessing noise and air pollution in a combined environmental pollutant index has been demonstrated.

\section{References}

APA. (2008). Directrizes para a elaboração de mapas de ruído. Portugal: Versão 2, Agência Portuguesa do Ambiente.

ATSDR. (1997). Toxicological profile for benzene. Atlanta, GA: U.S. Department of Health and Human Services. Public Health Service Agency for Toxic Substances and Disease Registry.

Bertellino, F., \& Licitra, G. (2000). I ModelliPrevisionali per ilRumore da TrafficoStradale Proc. of theAtti 2000 ConvegnoNazionaleTraffico e Ambiente 2000. Progetto Trento Ambiente Trento, Italia, (pp. 63-82).

Boschmann, E. E., \& Kwan, M.-P. (2008). Toward socially sustainable urban transportation: Progress and potentials. International Journal of Sustainable Transportation, 2(3), 138-157.

Carruthers, D. J., Blair, J. W., \& Johnson, K. L. (2003). Validation and sensivity study of the ADMS-Urban. Cambridge Environmental Research Consultants. TR-0191.

Carruthers, D. J., Edmunds, H. A., Bennett, M., Woods, P. T., Milton, M. J. T., Robison, R., et al. (1997). Validation of ADMS dispersion model and assessment of its performance relative to R-19 and ISC using archived LIDAR data. International Journal of Environment and Pollution, 8, 264-278.

Carruthers, D. J., Edmunds, H. A., Lester, A. E., McHugh, C. A., \& Singles, R. J. (1998) Use and validation of ADMS-Urban in contrasting urban and industrial locations. International Journal of Environment and Pollution, 14, 364-374.

CERC. (2001). ADMS-Urban user guide, version 1.6.

COPERT4. Available at: <http://lat.eng.auth.gr/copert> Accessed 2008.

CORINAIR. (2006). Emission inventory guidebook, version 5.0. September

Diário da República. (2007). Decreto-Lei no 9/2007, 17 de Janeiro. I Série-A, Lisboa. (2002). Directive 2002/49/EC of the European Parliament and of the Council of June 2002. Official Journal of the European Communities., pp. 12-25.

Hanna, S. R., \& Paine, R. J. (1989). Hybrid plume dispersion model (HPDM) development and evaluation. Journal of Applied Meteorology, 28, 206-224.

Highways Agency. (2007). Design manual for road and bridges: Vol. 11, Section 3, Part 1 - Air Quality. UK: Highways Agency.

King, R. P., \& Davis, J. R. (2003). Community noise: Health effects and management International Journal of Hygiene and Environmental Health, 206(2), 123-131.

King, E. A., Murphy, E., \& McNabola, A. (2009). Reducing pedestrian exposure to environmental pollutants: A combined noise exposure and air quality analysis approach. Transportation Research Part D, 14, 309-316.

Ko, J. H., Chang, S. I., Kim, M., Holt, J., \& Seong, J. C. (2011). Transportation noise and exposed population of an urban area in the Republic of Korea. Environment International, 7(2), 328-334.

McHugh, C. A., Carruthers, D. J., \& Edmunds, H. A. (1997). ADMS-Urban: An air quality management system for traffic, domestic and industrial pollution. International Journal of Environment and Pollution, 8(3-6), 666-675.

Murphy, E., \& King, E. A. (2010a). Scenario analysis and noise action planning: Modelling the impact of mitigation measures on population exposure. Applied Acoustics, doi:10.1016/j.apacoust.2010.10.006

Murphy, E., \& King, E. A. (2010b). Strategic environmental noise mapping: Methodological issues concerning the implementation of the EU Environmental Noise Directive and their policy implications. Environment International, 36, 290-298. 
Nagurney, A., Qiang, Q., \& Nagurney, L. (2010). Environmental impact assessment of transportation networks with degradable links in an era of climate change. International Journal of Sustainable Transportation, 4(3), 154-171.

NP 1730. (1996). Acústica, descrição e medição de ruído ambiente - Parte 1: Grandezas fundamentais e procedimentos; Parte 2: Recolha de dados relevantes para o uso do solo; Parte 3: Aplicação aos limites do Ruído. Lisboa.

O’Mahony, M., Gill, L.W., Broderick, B., English, L., Ahern, A., 2006. Scope of transport impacts on the environment. Environmental Research Technological Development and Innovation (ERTDI) Programme 2000-2006. Report Series No. 9. Washington.

Organisation for Economic Co-operation and Development. (1995). Roadside noise abatement: Report/prepared by an OECD scientific expert group. Washington DC: Organisation for Economic Co-operation and Development. OECD Publications and Information Center [distributor], Paris.

Pandian, S., Gokhale, S., \& Ghoshal, A. K. (2009). Evaluating effects of traffic and vehicle characteristics on vehicular emissions near traffic intersections. Transportation Research Part D, 14, 180-196.

Sabatino, S., Buccolieri, B., \& Bitter, R. (2005). Flow and pollutant dispersion modelling in a street canyon using Fluent and ADM-Urban. In 5th international conference on urban air quality Valencia, Spain, 29-31 March 2005.

Seinfeld, J. H., \& Padis, S. N. (1997). Atmospheric chemistry and physics from air pollution to climate change. John Wiley Sons.
Sharma, A. R., Kharol, S. K., \& Badarinath, K. V. S. (2010). Influence of vehicular traffic on urban air quality - A case study of Hyderabad, India. Transportation Research Part D, 15, 154-159.

Silva, L. T. (2008). Avaliação da Qualidade Ambiental Urbana. PhD Thesis, Universidade do Minho, Braga, Portugal.

Silva, L. T., Mendes, J. F. G., \& Ramos, R. A. R. (2010). Urban air dispersion model of a mid-sized city. Validation methodology. WSEAS Transactions on Environment and Development, 6(1), 1-10.

Timmis, R., Wilkinson, S., Carruthers, D., \& McHugh, C. (2000). Recent studies to validate and compare atmospheric dispersion models for regulatory purposes in the U.K. International Journal of Environment and Pollution, 14, 431-442.

WHO (World Health Organization). (2005). Air quality guidelines global update 2005, meeting report. Report on a working group meeting. Bonn, Germany: WHO.

WHO (World Health Organization). (2005). Night noise guidelines for Europe. WHO Regional Office for Europe.

WHO (World Health Organization). (2011). Burden of disease from environmental noise: Quantification of healthy life years lost in Europe. WHO Regional Office for Europe. http://www.euro.who.int/_data/assets/pdf_file/ 0008/136466/e94888.pdf

WG-AEN (European Commission Working Assessment of Exposure to Noise). (2006). Good practice guide for strategic noise mapping and the production of associated data on noise exposure, version 2. http://ec.europa.eu/environment/ noise/pdf/wg_aen.pdf 